\title{
O processo de apropriação do gênero textual em sua dupla possibilidade de abordagem escolar
}

\author{
The appropriation process of the textual genre in its \\ double possibility of school approach
El proceso de apropiación del género textual en su doble posibilidad de una abordaje escolar

\author{
MARILÚCIA DOS SANTOS DOMINGos STRIQUER*
}

\begin{abstract}
RESUMO
Partindo das concepções do Interacionismo Sociodiscursivo (ISD) sobre gêneros textuais e sobre instrumentos psicológicos (SCHNEUWLY, 2004) e de Rabardel (1995), a respeito de gênese instrumental, investigou-se em que medida os integrantes de um projeto de ensino integrado ao Pibid, que tem como base teórico-metodológica os gêneros textuais, apropriaram-se do gênero como um instrumento mediador e organizador do ensino da língua materna. De forma mais específica, a intenção, neste artigo, é conhecer se a base teórico-metodológica sobre os gêneros foi apropriada pelos membros do projeto após uma série de eventos. Para tanto, analisou-se um conjunto de respostas dadas pelos pibidianos a três diferentes questionários. Os resultados revelaram que a maioria dos investigados completou o processo da gênese instrumental, contudo dois deles demonstraram que a teoria estudada é ainda para eles artefato.
\end{abstract}

Palavras-chave: Gêneros textuais. Instrumentos psicológicos. Gêneses instrumental.

\begin{abstract}
Based on the concepts of Sociodiscursive Interactionism (SDI) on textual genres and on psychological instruments (SCHNEUWLY, 2004) and in Rabardel (1995) concerning instrumental genesis, we are interested in investigating the extent to which members of a teaching project integrated with Pibid, whose theoretical and methodological basis are related to the textual genres, appropriated the genre as a mediator instrument and organizer of mother tongue education. More specifically, our intention in this article is to know the theoretical and methodological basis on textual genres was appropriated by the project members after a series of events. Therefore, we analyzed a set of responses given by pibidianos to three different questionnaires. The results showed that most of the investigated participants completed the process of instrumental genesis, however two of them demonstrated that the studied theory is still for them artefact.
\end{abstract}

Keywords: Textual genres. Psychological instruments. Instrumental genesis.

\section{RESUMEN}

Partiendo de las concepciones del Interaccionismo Sociodiscursivo (ISD) sobre los géneros textuales y sobre los instrumentos psicológicos (SCHNEUWLY, 2004) y de Rabardel (1995) la respecto de la génese instrumental, interesamos en investigar en el que medida los integrantes de uno proyecto del enseñanza integrado al Pibid, tiendo como base teórico-metodológico los géneros textuales, hubieron apropriados de los géneros como un instrumento mediador y organizador de la enseñanza en la lengua materna. De manera más específica, nuestra intención, en este artículo, es saber si la base teórico-metodológico en los géneros fue apropiada por los miembros del proyecto después de una série de eventos. Así, analizamos un conjunto del respuestas ofrecida por los pibidianos en tres diferentes cuestionarios. Los resultados indicaron que la mayoría de los investigados ha completado el proceso, no obstante dos de ellos han demostrado que la teoría estudiada es para ellos un artefacto.

Palabras clave: Géneros textuales. Instrumentos psicológicos. Géneses instrumental.

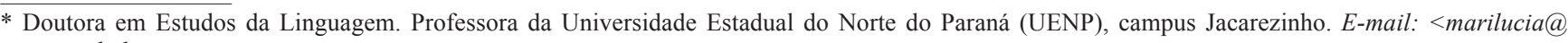
uenp.edu.br>.
} 


\section{INTRODUÇÃO}

Partindo das concepções do Interacionismo Sociodiscursivo (ISD) de que um gênero textual é um instrumento psicológico que "encontra-se entre o indivíduo que age e o objeto sobre o qual ou a situação na qual ele age" (SCHNEUWY, 2004, p. 23), e que para que esse instrumento possa se tornar efetivamente um mediador das ações de um indivíduo, é preciso que este dele se aproprie. Passando, assim, por um processo denominado por Rabardel (1995) de "gênese instrumental". O interesse neste estudo é investigar em que medida os integrantes de um projeto de ensino, que tem como base teórico-metodológica os gêneros textuais, apropriaram-se do gênero como um instrumento mediador e organizador do ensino da língua materna.

O referido projeto integra o Programa Institucional de Bolsas de Iniciação à Docência (Pibid) da Universidade Estadual do Norte do Paraná (Uenp), campus Jacarezinho, e é formado por duas coordenadoras, quatro professores da rede pública da educação básica e 22 alunos dos cursos de Letras da Uenp, os quais doravante são denominados de bolsistas ou pibidianos. Conforme as premissas básicas do Pibid, o objetivo do projeto é promover o contato direto dos acadêmicos dos cursos de licenciatura com as escolas da rede pública de ensino, a fim de colaborar para que tenham a oportunidade de conhecer a realidade da sala de aula antes da atuação docente. E ainda contribuir para a melhoria da qualidade da educação básica. Nesse sentido, a equipe do projeto, em conjunto, estuda as bases teóricometodológicas sobre gêneros textuais, elabora sequências e materiais didáticos, e os pibidianos realizam a transposição didática da teoria para as salas de aula da educação básica. Assim, são os primeiros e principais beneficiários do projeto, contudo não são os únicos, uma vez que, ao realizarem a transposição didática, os alunos da educação básica também passam a ser beneficiários em potencial.

De forma mais específica, esta investigação se centra em verificar se após os pibidianos terem participado durante um ano de estudos dirigidos, eventos científicos, elaboração de material de trabalho, observação e regência de sala de aula, tendo os gêneros como eixo organizador do ensino da língua materna, eles se apropriaram dos gêneros como instrumentos psicológicos e mediadores das ações pedagógicas. No entanto, o foco é sobre a apropriação dos conceitos teórico-metodológicos a respeito dos gêneros, uma vez que investigar se estes são efetivamente instrumentos na prática pedagógica demandaria outros métodos e instrumentos de análise. A intenção, neste artigo, é, portanto, conhecer se a base teórico-metodológica sobre os gêneros foi apropriada pelos membros do projeto. Além de verificar sea após a série de eventos dos quais os pibidianos participaram, eles estão prontos para fazer uso dos gêneros em sua dupla possibilidade de abordagem escolar, "como instrumento semiótico que materializa e significa uma prática social e como instrumento a ser apropriado pelo aprendiz no processo de instrumentalização que sustenta e orienta a ação de um sujeito em uma prática social de referência" (DOLZ et al., 2008 apud NASCIMENTO, 2009, p.9). Ressalta-se que a pesquisa se estabeleceu sobre o conhecimento teórico dos pesquisados, já que o corpus de análise se constituiu de respostas dadas pelos pibidianos a três diferentes questionários. O primeiro respondido por eles no início do projeto, o segundo após uma série de eventos e o terceiro após um ano de projeto e participação em vários eventos de estudo e práticas pedagógicas.

A organização deste estudo se faz com a apresentação do aporte teórico do ISD na definição de gênero como um instrumento (SCHNEUWLY, 2004), a qual tem origem nos estudos de Vygotsky (2007) e Rabardel (1995). Em seguida, expõem-se as análises e os resultados destas recorrentes sobre as respostas aos questionários. E, por fim, apontam-se algumas considerações finais.

\section{GÊNEROS, INSTRUMENTOS, GÊNESE INSTRUMENTAL}

De acordo com Machado e Lousada (2010), a concepção de gêneros apresentada por Schneuwly (2004) foi construída à luz da psicologia de Vygotsky. Para Schneuwly (2004, p. 27), o gênero é um instrumento que fornece ao sujeito as bases da comunicação, permitindo que ele aja com a linguagem em diferentes situações, já que representa a realidade, as diferentes práticas discursivas existentes. Dessa forma, para Schneuwly, que foi quem, de acordo com Machado e Cristovão (2006, p. 550-551), acabou fornecendo "uma das concepções mais vigorosas para a questão do ensino e da aprendizagem de gêneros e para a elaboração de materiais didáticos adequados", o gênero é definido e caracterizado como "um instrumento semiótico complexo" (SCHNEUWLY, 2004, p. 27). Para agir sobre um objeto ou situação, o indivíduo se utiliza de um instrumento mediador que se constitui de duas faces. De um lado, está o artefato, como parte do instrumento, e do outro, como outra parte integrante, está(ão) o(s) esquema(s) de utilização do artefato. Por exemplo, para que um indivíduo participe de uma prova de redação de vestibular é preciso que ele saiba produzir o gênero textual redação, que, como um instrumento que está entre o candidato e a situação comunicativa e específica do vestibular, é formado pelo artefato: a redação como um texto concreto e por meio de esquemas de utilização. É necessário que o candidato conheça todos os elementos que constituem social, comunicativa e linguisticamente o gênero: a esfera e a prática social da qual emerge o 
gênero, a função comunicativa, o veículo que faz circular, as condições de produção, a infraestrutura textual (BAKHTIN, 2003; BRONKART, 2009).

$\mathrm{O}$ conceito de instrumento constituído pelo ISD tem origem na perspectiva vygotskyana de que as funções superiores do psiquismo humano foram construídas historicamente, na base da criação do trabalho e dos instrumentos. De acordo com Vygotsky (2007, p. 26), o trabalho humano e o uso de instrumentos são "os meios pelos quais o homem transforma a natureza e, ao fazê-lo, transforma a si mesmo". Existem dois tipos de instrumentos: o material ou físico e o psicológico ou semiótico. Os materiais são, por exemplo, recorrendo à exemplificação realizada por Nascimento (2012) sobre aqueles disponíveis no ambiente docente, os slides, o quadro negro, os laboratórios. E os psicológicos são os signos, as palavras, os conceitos, os gêneros "ferramentas que auxiliam nos processos psicológicos e não nas ações concretas" como as ferramentas materiais (VYGOTSKY, 2007, p. 30).

Portanto, a diferença essencial entre o instrumento material e o psicológico é a de que o primeiro serve para que o indivíduo transforme a natureza externa, enquanto o segundo orienta o que é interno, pois se dirige para o controle do próprio indivíduo $\mathrm{E}$ o auxilia na solução de problemas psicológicos como lembrar, representar, comparar, relatar, planejar, entre outras ações internas ${ }^{1}$.

Para Vygotsky, os instrumentos psicológicos, uma vez internalizados, provocam "transformações comportamentais e estabelecem um elo de ligação entre as formas iniciais e tardias do desenvolvimento individual" (VYGOTSKY, 2007, p. 26). Ou seja, o desenvolvimento se opera por consequência não apenas do uso de instrumentos pelo homem, mas, sobretudo, pelo fato de que os instrumentos, ao carregarem a cultura material, os conhecimentos historicamente elaborados, possibilitam que o homem internalize operações mentais e físicas. E possa também lidar com aquele instrumento e realizar adaptações que permitam que o instrumento seja utilizado em novas situações.

A base de todo o pensamento vygotskiano é a relação do homem com o mundo, uma relação mediada, e os elementos mediadores são os instrumentos materiais e os psicológicos, os quais são determinantes para o desenvolvimento psíquico de um sujeito. O instrumento é "um meio de influência do sujeito sobre si mesmo, um meio de autorregulação e de autocontrole" (FRIEDRICH, 2012, p. 57).

\footnotetext{
${ }^{1}$ De acordo com Friedrich (2012, p. 53), "o conceito de instrumento psicológico foi desenvolvido por Vygotsky em forma de teses no pequeno texto 'O método instrumental em psicologia' (1930) e nos dois primeiros capítulos da obra A história do desenvolvimento das funções psíquicas superiores (1931)" (grifos da autora).
}

Ainda de acordo com Vygotsky, os instrumentos são, primeiro, marcas externas, depois se transformam em processos internos, ou seja, passam a se configurar em uma representação mental daquilo que existe no mundo externo. E é exatamente o mecanismo externo-internoexterno que o teórico chama de processo de internalização (VYGOTSKY, 2007).

O externo seria o resultado das interações do indivíduo com um grupo cultural, isto é, o processo de internalização inicia-se com uma atividade externa, no nível social, entre pessoas (processo interpsicológico), e depois de passar por uma reconstrução interna, o segundo momento, por uma "longa série de eventos ocorridos ao longo do desenvolvimento" (VYGOSTKY, 2007, p. 58), chega ao nível individual, ao interior (processo intrapsicológico). A operação externa (interpessoal), já organizada e reconstruída internamente (intrapessoal), é, então, exteriorizada, o terceiro momento do processo.

Essa concepção de Vygotsky, de instrumento e de seu processo de internalização, foi reinterpretada por Rabardel (1995), para quem um instrumento ou ferramenta é sempre formado por duas faces. De um lado do instrumento, tem-se o artefato, e de outro, os esquemas de utilização do artefato. Voltando ao mesmo exemplo, ao propor a um candidato que produza uma redação em uma prova de vestibular, o gênero seria, então, de acordo com Rabardel (1995), apenas um artefato. Ainda não é um elemento mediador da ação humana do candidato. Para se chegar à gênese instrumental, que é para Rabardel (1995) o resultado da apropriação em que o artefato se transforma em instrumento, o processo é longo e complexo, devido à integração entre a atividade da pessoa, seus conhecimentos, a maneira e os métodos com os quais ela trabalha. E também pelo fato de o artefato necessitar de um determinado tempo físico e psicológico, por vezes mais, por vezes menos, dependendo do instrumento, da atividade, da pessoa e da incorporação do artefato a seus componentes psicológicos.

É quando a pessoa se apropria do artefato, atendendo às suas necessidades internas, ou seja, quando esquemas já foram adaptados para utilização, já foram integrados à estrutura cognitiva do usuário, e quando o artefato já faz parte de uma realidade externa (social) daquela pessoa. E também por isso ela o utiliza, já que o artefato é considerado, depois de todo esse processo, como construído pela pessoa, pois foi por ela adaptado para si e para o meio, tornando-se um instrumento. Portanto, quando o indivíduo se apropria ${ }^{2}$ do gênero é porque ele desenvolveu as capacidades de linguagem necessárias para produzir uma redação em um processo de vestibular.

\footnotetext{
2 Ao reinterpretar a noção de instrumento de Vygotsky, Rabardel utiliza-se do termo apropriação e não internalização como Vygotsky.
} 
Portanto, para Rabardel (1995), a gênese instrumental é um duplo processo de apropriação de instrumentos: quando o artefato é integrado à estrutura cognitiva da pessoa, ela acaba por enriquecer seus esquemas mentais de uso de artefatos e ocorre o processo chamado pelo autor de instrumentação. Os instrumentos coordenam, transformam, atualizam os esquemas já existentes nas estruturas cognitivas. Já quando a pessoa faz adaptações no artefato por funcionalidades e finalidades específicas, quando o artefato é enriquecido, o processo é o de instrumentalização.

Com base nessas concepções, Schneuwly (2004) metaforiza o gênero textual como instrumento semiótico, e os estudiosos do ISD passam a considerá-lo um "megainstrumento". Isto é, o gênero textual é, de acordo com Schneuwly (2004, p. 28), "uma configuração estabilizada de vários subsistemas semióticos (sobretudo linguísticos, mas também paralinguísticos), permitindo agir eficazmente numa classe bem definida de situações de comunicação".

Por assim ser, a partir dos estudos de Schneuwly (2004), o gênero é concebido em uma dupla possibilidade de abordagem escolar, por exemplo, no caso do projeto de ensino em questão, os gêneros ${ }^{3}$ são os objetos/conteúdos escolares a serem ensinados pelos pibidianos aos alunos da educação básica $\mathrm{O}$ objetivo é levar o aluno a aprender a produzir/interpretar gêneros e a utilizá-los em práticas discursivas escolares, principalmente fora da escola, em situações reais de uso da língua. Ao mesmo tempo, estes são utilizados pelos pibidianos como guia para o ensino das suas especificidades, das suas dimensões e das suas operações de uso. É o instrumento mediador utilizado por eles para agir sobre os alunos, para levá-los a aprender a produzir o gênero em questão.

\section{OS PIBIDIANOS E O PROCESSO DE APROPRIAÇÃO DOS GÊNEROS}

O projeto Pibid abordado neste artigo iniciou suas atividades em março de 2014, e no primeiro encontro com toda a equipe, os coordenadores ofereceram aos bolsistas ID um questionário para diagnosticar os saberes sobre os gêneros textuais. Uma das perguntas foi: qual seu conhecimento a respeito da teoria dos gêneros textuais (Bakhtin, Bronckart, entre outros teóricos)? As respostas revelaram que 12 pibidianos, 59\% dos 21 , já tinham tido contato, de alguma forma, com a base teórica em questão, sendo que, desses 12, 10 deles tiveram contato em disciplinas na graduação, no curso de Letras da Uenp, do qual todos eles são discentes; um em grupos de

\footnotetext{
3 Os gêneros textuais tomados em dupla abordagem escolar peloprojeto Pibid/Uenp são: o artigo de opinião como redação de vestibular; a redação do Exame Nacional do Ensino Médio (ENEM) nos terceiros anos do ensino médio; e o causo (caso?) no sexto ano do ensino fundamental.
}

pesquisa; e um em estudos independentes. Mas outros nove bolsistas (41\%) afirmaram não terem conhecimento a respeito dos gêneros.

Após esse diagnóstico, deu-se início, em março de 2014, aos estudos presenciais e à modalidade a distância com toda a equipe do projeto; aos estudos dirigidos pelas coordenadoras de área centrados na leitura e no debate de obras sobre gêneros do discurso (BAKHTIN, 2003); ao dialogismo (BAKHTIN; VOLOCHINOV, 2006); aos gêneros textuais e procedimentos de análise de textos (MARCUSCHI, 2005; BRONCKART, 2009; BRONCKART; MACHADO, 2004); à elaboração de sequências didáticas (DOLZ; NOVERRAZ; SCHNEUWLY, 2004); e às orientações para a prática docente na educação básica (PARANÁ, 2009) 4 . Ao final dessa primeira série de estudos, em junho de 2014, ofereceu-se aos 21 pibidianos ID o segundo questionário, tendo como uma das questões "O que são os gêneros discursivos/textuais?".

Das 21 respostas, 15 delas demonstraram que esse conjunto de bolsistas ID, ou seja, 71\% dos pibidianos, alcançou apenas uma compreensão superficial dos enunciados proferidos, uma vez que as respostas não apresentaram nenhum tipo de complementação ou transformação dos textos de estudo, tampouco a voz dos respondentes se fez presente nos textos-respostas, que são apenas cópias ou paráfrases dos textos estudados.

\section{Exemplo 1:}

Uma atividade humana, de forma que sejam considerados como inseparáveis do gênero o conteúdo temático, o estilo e a estruturação formal, bem como a situação comunicativa da qual ele participa, as condições de produção. O conteúdo temático, o estilo, a construção composicional estão ligados no todo enunciado dos gêneros.

Exemplo 2:
Gêneros discursivos são textos comunicativos ou enunciados usados nas diferentes formas de comunicação. São três elementos: o conteúdo temático, o estilo e a construção composicional, os quais estão ligados ao gênero, especificando determinado campo da comunicação.

\footnotetext{
${ }^{4}$ BAKHTIN, M. Estética da criação verbal. 4. ed. São Paulo: Martins Fontes, 2003.

BAKHTIN, M.; VOLOCHINOV, V. Marxismo e filosofia da linguagem. 12. ed. São Paulo: Hucitec, 2006.

BRONCKART, J. P. Atividade de linguagem, textos e discurso: por um Interacionismo Sociodiscursivo. 2. ed. São Paulo: EDUC, 2009.

BRONCKART, J. P.; MACHADO, A. R. Procedimentos de análise de textos sobre o trabalho educacional. In: MACHADO, A. R. (org.). O ensino como trabalho: uma abordagem discursiva. Londrina: Eduel, 2004, p. 131-163.

DOLZ, J.; NOVERRAZ, M.; SCHNEUWLY, B. Sequências didáticas para o oral e a escrita: apresentação de um procedimento. In: SCHNEUWLY, B.; DOLZ, J. e cols. Gêneros orais e escritos na escola. Campinas: Mercado das Letras, 2004., p. 95-128.

PARANÁ. Diretrizes Curriculares de Língua Portuguesa para os anos finais do Ensino Fundamental e Ensino Médio. Curitiba/PR: SEED, 2009.
} 
Os respondentes, de acordo com os exemplos, os quais representam significativamente os demais do conjunto de 15 , nem ao menos conseguem articular as partes copiadas dos textos que foram estudados e construir paráfrases em uma sintaxe adequada. Portanto, 15 pibidianos marcaram em suas respostas que a base teórica sobre gêneros ainda era, naquele momento, para eles, um artefato. Os conceitos estavam exteriores a eles (RABARDEL, 1995), mesmo para alguns daqueles 12 que afirmaram no questionário do primeiro encontro que tinham tido contato com a base teórica dos gêneros. Talvez a apropriação não tenha ocorrido porque o processo pelo qual esse conjunto de pessoas passou não tenha se constituído como longo e complexo, conforme define Rabardel (1995). Ou ainda como uma longa série de eventos no sentido vygotskiano, tanto em relação ao tempo, já que foram quatro meses de estudos, como sobre a complexidade dos eventos. Apesar de terem sido realizados estudos individualizados, debates em grupos, abordagem aos conceitos teórico-metodológicos por meio de slides, exercícios, exemplificações. E uma parte dos 15 pibidianos chegou a ter contato com o conteúdo nas disciplinas do curso de graduação. $\mathrm{Na}$ operação de exteriorização dos conceitos (VYGOTSKY, 2007), não há reconstrução, há apenas reprodução do que ainda é externo a 15 pibidianos.

Já entre as respostas dos outros seis pibidianos, $29 \%$ do total demonstrou o referido enriquecimento de esquemas mentais, apresentando a instrumentação e também a instrumentalização, uma vez que suas respostas eram formadas por exemplos. O que mostra que esses indivíduos já conseguem fazer adaptações nos conceitos abordados (RABARDEL, 1995). Exemplo:

Os gêneros textuais são representantes das práticas discursivas realizadas pela sociedade. São textos comunicativos ou enunciados dotados de função social. Os gêneros textuais são incontáveis, uma vez que podem ser desde um gênero informal, como uma conversa, até um mais formal, como um artigo acadêmico. Segundo Bakhtin, os gêneros são formas relativamente estáveis de enunciado e transmitem as finalidades e condições específicas de cada campo de atividade humana por meio de três elementos indissoluvelmente ligados ao enunciado em si: o conteúdo temático, o estilo e a construção composicional. De acordo com Marcuschi, os gêneros são caracterizados por serem eventos textuais maleáveis e dinâmicos e surgem conforme a necessidade de interação social, assim como na relação com novas formas de tecnologia. E, ainda segundo Marcuschi, 'caracterizam-se muito mais por suas funções comunicativas, cognitivas e institucionais do que por suas peculiaridades linguísticas e estruturais'.

O conceito teórico de gênero é, para o aluno autor dessa resposta e para os outros cinco, um instrumento semiótico (SCHNEUWLY, 20004). A possibilidade, diante da hipótese de terem sido construídos anteriormente sobre o outro conjunto, é que esses seis pibidianos façam parte do grupo daqueles que já tiveram contato com a base teórica sobre os gêneros na graduação, em grupo de estudo e de forma independente. Isto é, passaram por uma longa série de eventos, no sentido vygotskiano da expressão, quantitativa e qualitativamente maior do que os outros 15 pibidianos.

Ressalta-se que, diante dos resultados encontrados para o segundo questionário, uma série de novos estudos foram organizados pelas coordenadoras do projeto, incluindo: reestudos e novas discussões a respeito das obras estudadas e de outros de diferentes autores; orientação de pesquisas que culminaram em artigos científicos, as quais foram publicadas em periódicos científicos e divulgadas em seminários e congressos; elaboração de materiais didáticos; observação de sala de aula; regência de algumas aulas para implementação dos materiais didáticos confeccionados. Assim, após oito meses da aplicação do segundo questionário, um ano do início do projeto e da realização de mais uma longa série de eventos (VYGOTSKY, 2007), ofereceu-se aos bolsistas ID um terceiro questionário, do qual a mesma questão participou: "O que são gêneros discursivos/textuais?". E as respostas revelaram que, dos 21 pibidianos, 19 deles, $90 \%$, apropriaram-se da definição teórica sobre o que são os gêneros textuais. Exemplo:

\begin{abstract}
Vou resumir. Os gêneros textuais são representantes de práticas sociocomunicativas, práticas essas que são situações de comunicação por meio da linguagem que se originam nos mais variados campos de atividade humana (ex.: religioso, escolar, etc.). Então os gêneros são textos comunicativos com funções sociais e podem ser desde uma simples conversa até um artigo científico, e são compostos por três elementos que não podem ser separados: o conteúdo temático, a construção composicional e o estilo.
\end{abstract}

Destaca-se o fato de esse bolsita e da maioria dos 19 terem apresentado exemplificações em suas respostas, evidenciando que ao exteriorizarem o que eles conhecem já conseguem fazer adaptações à palavra de outros (teóricos, coordenadoras) (RABARDEL, 1995) em uma aproximação da teoria às situações práticas. Um outro fato que merece destaque é o emprego da expressão "vou resumir". O pibidiano demonstrou que para ele o conceito era tão claro, e sobre isto ele sabia tanto, que até poderia fazer uma síntese.

Contudo, ainda para dois pibidianos não ocorreu a apropriação. Um deles simplesmente deixou a resposta em branco e o outro apresentou como resposta um ponto de exclamação, anunciando explicitamente que ainda não 
havia compreendido os conceitos em questão. Esses dois demonstraram que precisam ainda integrar os conceitos às suas atividades, necessitando mais tempo físico e psicológico (RABARDEL, 1995), mais eventos para que o processo de internalização ocorra (VYGOTSKY, 2007) e para que a teoria se torne instrumento semiótico para eles.

\section{CONSIDERAÇÕES FINAIS}

Investigou-se neste projeto em que medida os bolsistas ID integrantes de um projeto de ensino Pibid/Uenp se apropriaram da base teórico-metodológica sobre os gêneros textuais, uma vez que esse é o eixo organizador deste trabalho de ensino. Partiu-se da premissa do ISD de que para que um instrumento semiótico - como é o caso de todo e qualquer conceito e de todo e qualquer gênero textual - possa ser um mediador das ações de um indivíduo, é preciso que do instrumento o indivíduo se aproprie. Os resultados revelaram que, após a participação dos 21 pibidianos em uma longa série de eventos (VYGOTSKY, 2007) físicos e psicológicos (RABARDEL, 1995), a maioria, 19 deles, apropriou-se da base teórico-metodológica. Sendo que apenas dois bolsistas ID demonstraram em suas respostas aos questionários aplicados que ainda precisavam de mais ou de diferentes eventos para que o processo da gênese instrumental se realizasse.

Contudo, de acordo com Rabardel (1995), compreende-se que o fato de esses dois pibidianos não terem ainda se apropriado dos conceitos em questão é um processo natural devido à complexidade que se constitui a gênese instrumental. Esta, segundo o autor, completa-se dependendo não só da maneira e do método com os quais se trabalha para atingi-la, mas também do próprio indivíduo visto de maneira particularizada.

\section{REFERÊNCIAS}

BAKHTIN, Mikail. Estética da criação verbal. Tradução Maria Ermantina Galvão G. Pereira. 4. ed. São Paulo: Martins Fontes, 2003.

BAKHTIN, M.; VOLOCHINOV, V. Marxismo e filosofia da linguagem. 12. ed. São Paulo: Hucitec, 2006.

BRONCKART, Jean Paul. Atividade de linguagem, textos e discurso: por um Interacionismo Sociodiscursivo. Tradução Anna Rachel Machado e Péricles Cunha. 2. ed. São Paulo: Educ, 2009.
BRONCKART, J. P.; MACHADO, A. R. Procedimentos de análise de textos sobre o trabalho educacional. In: MACHADO, A. R. (org.). O ensino como trabalho: uma abordagem discursiva. Londrina: Eduel, 2004, p. 131-163.

DOLZ, J.; NOVERRAZ, M.; SCHNEUWLY, B. Sequências didáticas para o oral e a escrita: apresentação de um procedimento. In: SCHNEUWLY, B.; DOLZ, J. e cols. Gêneros orais e escritos na escola. Campinas: Mercado das Letras, 2004., p. 95-128.

FRIEDRICH, Janette. Lev Vigotski: mediação, aprendizagem e desenvolvimento - uma leitura filosófica e epistemológica. Tradução Anna Rachel Machado e Eliane Gouvêa Lousada. Campinas: Mercado de Letras, 2012.

MACHADO, Anna Raquel; CRISTOVÃO, Vera Lúcia Lopes. A construção de modelos didáticos de gêneros: aportes e questionamentos para o ensino de gêneros. Linguagem em (Dis)curso, Tubarão/SC, v. 6, n. 3, p. 547-573, set./dez. 2006.

MACHADO, Anna Raquel; LOUSADA, Eliane. A apropriação de gêneros textuais pelo professor: em direção ao desenvolvimento pessoal e à evolução do 'méttier'. Linguagem em (Dis)curso, Palhoça/SC, v. 10, n. 3, p. 629-633, set./dez. 2010

NASCIMENTO, Elvira Lopes (org.). Gêneros textuais: da didática das línguas aos objetos de ensino. São Carlos: Claraluz, 2009.

Mediações formativas na perspectiva do Interacionismo Sociodiscursivo. Mesa-Redonda Práticas Docentes na Educação Profissional: perspectivas e desafios. II Seminário das Áreas de Conhecimento da Base Comum: aprendizagens na educação profissional técnica e tecnológica. Dourados, MT: Instituto Federal de Educação, Ciência e Tecnologia (UFMT), 2012. Cópia interna.

PARANÁ. Diretrizes Curriculares de Língua Portuguesa para os anos finais do Ensino Fundamental e Ensino Médio. Curitiba: SEED, 2009.

RABARDEL, Pierre. Les hommes et les technologies. Approche cognitive des instruments contemporains. Paris: Armand Colin, 1995.

SCHNEUWLY, Bernard. Gêneros e tipos de discurso: considerações psicológicas e ontogenéticas. In: SCHNEUWLY, Bernard; DOLZ, Joaquim. Gêneros orais e escritos na escola. Tradução e organização Roxane Rojo e Glaís Sales Cordeiro. Campinas: Mercado das Letras, 2004. p. 21-40.

VYGOTSKY, Levi Semenovitch. A formação social da mente: o desenvolvimento dos processos psicológicos superiores. Organizadores Michael Cole et al. Tradução José Cipolla Neto, Luís Silveira Menna Barreto, Solange Castro Afeche. 7. ed. São Paulo: Martins Fontes, 2007.

Submetido em 29/06/2015

Aprovado em 71/02/2016

\author{
referências conferir com original \\ cits em p. 360 (v. rodapé)
}

